This is the author's final, peer-reviewed manuscript as accepted for publication. The publisher-formatted version may be available through the publisher's web site or your institution's library.

\title{
Labor supply, income, and welfare of the farm household
}

Yang-Ming Chang, Biing-Wen Huang, and Yun-Ju Chen

\section{How to cite this manuscript}

If you make reference to this version of the manuscript, use the following information:

Chang, Y., Huang, B., \& Chen, Y. (2012). Labor supply, income, and welfare of the farm household. Retrieved from http://krex.ksu.edu

\section{Published Version Information}

Citation: Chang, Y., Huang, B., \& Chen, Y. (2012). Labor supply, income, and welfare of the farm household. Labour Economics, 19(3), 427-437.

Copyright: (C) 2012 Elsevier B.V.

Digital Object Identifier (DOI): doi:10.1016/j.labeco.2012.03.004

Publisher's Link: http://www.sciencedirect.com/science/article/pii/S0927537112000231

This item was retrieved from the K-State Research Exchange (K-REx), the institutional repository of Kansas State University. K-REx is available at http://krex.ksu.edu 
Forthcoming in Labour Economics

\title{
Labor Supply, Income, and Welfare of the Farm Household
}

\author{
by \\ Yang-Ming Chang ${ }^{*}$, Biing-Wen Huang ${ }^{\dagger}$, and Yun-Ju Chen ${ }^{\ddagger}$
}

First submission: January 14, 2011

This revised edition: March 6, 2012

\begin{abstract}
Considering family labor and hired labor as heterogeneous inputs, we present a theoretical framework in which the optimal decisions of a farm household on on-farm family and hired labor, off-farm labor supply, and leisure are determined uniquely and endogenously. Focusing on two alternative settings with and without off-farm employment constraints, we show that imperfect substitutability between family labor and hired labor is not critical to the separation of household production and consumption. The validity of the separation proposition is shown to depend crucially on whether or not the availability of off-farm job opportunities is limited. We further examine how changes in external economic conditions and government policies affect the time allocation decisions of the household, as well as the composition of household income (i.e., on-farm income and off-farm labor earnings).
\end{abstract}

Keywords: Off-farm labor supply; Family and hired labor; Off-farm employment constraints JEL Classifications: D1, J2, Q1

*Department of Economics, Kansas State University, 319 Waters Hall, Manhattan, KS 66506, U.S.A., Tel: (785) 532-4573, Fax: (785) 532-6919, Email: ymchang@ksu.edu

${ }^{\dagger}$ Department of Applied Economics, National Chung-Hsing University, Taichung, Taiwan 402, Tel: (04) 228-40350, Fax: (04)2286-0255, Email: bwhuang@nchu.edu.tw

${ }^{\ddagger}$ Department of Applied Economics, National Chung-Hsing University, Taichung, Taiwan 402, Tel: (04)2284-0350 Ext. 201, Fax: (04)2286-0255, Email: yjc2010@nchu.edu.tw

We thank the editor, Ian Walker, and anonymous referees for valuable comments and suggestions that have improved the quality of the paper. We also thank Andrew Barkley, Terry Kastens, and Shane Sanders for valuable comments. The remaining errors are ours. 


\section{Introduction}

Issues on the separation of production and consumption decisions in the farm household have long been of interest to economists. ${ }^{1}$ The farm household is characterized by a dual role in producing marketable output and coordinating consumption of its members through the allocation of time between work (on-farm and/or off-farm) and leisure. Investigating the separation proposition is important because separation allows for independent estimation of production and consumption, on the one hand, and serves as a foundation for the separate supply and demand analyses in the neoclassical economics, on the other. In a seminal contribution, Benjamin (1992) raised an important issue concerning whether the validity of the separation hypothesis ceases to hold when "family and hired labor are not perfect substitutes in production" (p. 290). One question of interest is: Would studies showing that family and hired labor are imperfect substitutes be sufficient to undermine the separation proposition?

In this paper, we show that imperfect substitutability between family and hired labor is not critical to the separation between household production and consumption. Interestingly, the validity of the separation proposition depends crucially on whether or not the availability of offfarm job opportunities is limited. To allow for imperfect substitutability, we incorporate a neoclassical-type production function into the traditional income-leisure framework and examine the labor supply and production decisions of a farm household in which family and hired labor are heterogeneous. The assumption of the heterogeneity of labor inputs is supported by several studies on agrarian production. ${ }^{2}$ In particular, this assumption parallels Schultz's (1999, p. 7) observation that "family and hired labor may exhibit different productivity and may deserve to be treated as separate inputs.”

In the analysis, we first present a model with flexible off-farm job opportunities to characterize the endogenous behavior of a farm household in which on-farm family and hired labor, off-farm labor supply, and leisure are uniquely determined. We further analyze the case with off-farm job constraints. Based on the alternative settings, we examine how changes in

\footnotetext{
${ }^{1}$ See, e.g., Barnham and Squire (1979), Strauss (1984, 1986), Lopez (1986), Singh, Squire, and Strauss (1986), Huffman (1991), Benjamin (1992), Schultz (1999), Woldehanna, Lansink, and Peerlings (2000), Taylor and Adelman (2003), Benjamin and Kimhi (2006), Kwon, Orazem, and Otto (2006), Hennessy and Rehman (2008), and Lien, Kumbhakar, and Hardaker (2010).

2 See, e.g., Deolalikar and Vijverberg (1983, 1987), Eswaran and Kotwal (1986), Fafchamps and Quisumbing (1999), Frisvold (1994), Jacoby (1993), Schultz (1999),and Benjamin and Kimhi (2006).
} 
economic conditions and government policies affect the labor and production decisions of the household. Further, we discuss the effects of these external changes and government policies on total household income and its composition (i.e., on-farm income and off-farm labor earnings), as well as on household welfare (i.e., utility). Special emphasis is placed on the interaction of the farm household with off-farm or non-farm job markets.

Studies concerning the effects of non-farm employment opportunities on farm labor, production, and income can be traced back to 1960s and 1970s. ${ }^{3}$ With long-term growth in nonfarm sectors, it has been observed that agricultural households in many countries (especially the developed countries such as the United States and the European Union) are increasingly interacting with external labor markets either as a way of improving household income or as an option for income diversification. Several studies have documented that income from off-farm activities constitutes an increasingly important part of total household income for farmers. ${ }^{4}$ For agricultural households in the United States, for example, it has been shown that there is a positive correlation between farm income variability and off-farm employment, and that off-farm labor earnings play a prominent role for income diversification (Mishra and Goodwin, 1997). Other interesting observations include that farm women's participation in the off-farm labor markets has been increasing and that the majority of farm women in the U.S. are now employed off the farm (Findeis, 2002). In light of the facts, ${ }^{5}$ we pay particular attention to the behavior of a farm household in adjusting its labor supply between farm work and off-farm employment.

Our analytical framework extends the income-leisure model of Benjamin (1992), that treats family and hired labor as perfect substitutes. Benjamin tested empirically for the optimal decisions of farm households, and found empirical results in support of the separation hypothesis. In a model with homogeneous labor inputs and flexible off-farm job opportunities, Benjamin found that the optimal mix of family and hired labor is theoretically indeterminate (1992, p. 291). We show that this indeterminacy problem can be resolved by the heterogeneity approach in

\footnotetext{
${ }^{3}$ See, e.g., Nakajima (1969), Bowles (1970), and Youtopoulus and Lau (1974).

${ }^{4}$ See e.g., Anderson and Leiserson (1980), Rosenzweig (1988), Ahearn and Lee (1991), Jacoby (1993), Newman and Gertler (1994), and Mishra and Sandretto (2002).

${ }^{5}$ Technological improvements in the production of agricultural products have resulted in farmers either leaving production agriculture or finding part-time jobs in the non-farm sectors (see, e.g., Barkley 1990; Gardner 1992; Ahearn and Lee 1997). Changes in external economic conditions and government policies also contribute to the adjustments of farm households in labor supply, production, and consumption decisions. For contributions regarding the reallocation of labor between farm and non-farm work from a household's perspective see, e.g., Huffman (1976, 1980), Sumner (1982), Benjamin (1992), and Caillavet, Guyomard, and Lifran (1994).
} 
which family and hired labor are treated as separate inputs (Schultz, 1999). Moreover, we show that the imperfect substitutability of family and hired labor is not critical in undermining the separation proposition. One critical element to the separation between household production and consumption is the availability of off-farm employment opportunities.

The remainder of the paper is organized as follows. Section 2 presents a farm household model in which off-farm employment is flexible and the equilibrium in family and hired labor is unique. Section 3 presents a model with off-farm employment constraints. Section 4 concludes.

\section{A Model with Flexible Off-Farm Job Opportunities}

\subsection{The Analytical Framework}

Following the farm household literature, we adopt the traditional income-leisure approach to examine the labor supply and production decisions of a farm family. The household's preferences are defined over income $(I)$ and leisure $(L)$ : $U=U(I, L)$. We assume this utility function is twice continuously differentiable and strictly quasi-concave, which implies that indifference curves are strictly convex.

With respect to farm production, we consider the case where there is imperfect substitutability between on-farm family and hired labor. This consideration parallels Schultz's (1999) observation that the two labor inputs may not be good substitutes "because of differences in relevant skills and farm-specific management experience, or because incentive and monitoring costs differ in these tasks for family and hired labor” (p. 7). ${ }^{6}$ For simplicity we assume that farm production is given by $Q=G(F, H ; A)$, where $Q$ represents a main agricultural output, $F$ is onfarm family labor, $H$ is hired-in labor, and $A$ is fixed or exogenously given such as land. The production function is twice continuously differentiable and strictly concave in labor inputs, i.e.,

$$
\begin{aligned}
& G_{F}=\frac{\partial G}{\partial F}>0, G_{H}=\frac{\partial G}{\partial H}>0, G_{F F}=\frac{\partial^{2} G}{\partial F^{2}}<0, G_{H H}=\frac{\partial^{2} G}{\partial H^{2}}<0, \\
& \text { and } G_{F F} G_{H H}-G_{F H}^{2}>0 \text {, where } G_{F H}=G_{H F}=\frac{\partial^{2} G}{\partial F \partial H}=\frac{\partial^{2} G}{\partial H \partial F} .
\end{aligned}
$$

These assumptions indicate that the positive marginal product of each labor input is subject to

\footnotetext{
${ }^{6}$ There are several important studies that also treat hired labor as another variable input in farm production. See, e.g., Strauss (1986) and Huffman $(1980,1991)$.
} 
diminishing returns. Family and hired labor may be technologically complement $\left(G_{F H}>0\right)$ or substitute $\left(G_{F H}<0\right)$.

Given the assumption that family and hired-in labor are heterogeneous, there are two competitive labor markets: one for hired-in labor whose wage rate is $w_{h}$ and the other for offfarm family labor whose wage rate is $w_{o}$. We assume that off-farm wage is higher than hiring-in wage, i.e., $w_{o}>w_{h}$. This assumption is consistent with the facts that farm households' participation in the off-farm labor markets and their off-farm earnings have been increasing (Mishra and Sandretto, 2002).

In this section, we focus the analysis on the case of a flexible off-farm work schedule. The household allocates its time between on-farm work ( $F$ ), off-farm employment ( $M$ ), and leisure ( $L$ ), where $M=T-F-L$ and $T$ is the household's total time endowment in a given period. Because of on-farm work and off-farm employment, there are two sources of labor incomes for the household. One is on-farm income, which is defined as farm revenues net of wage payments to hired-in labor, $y_{f} \equiv p G(F, H ; A)-w_{h} H$, where $p$ represents the competitive price of the farm product. The other source of income is off-farm labor earnings, defined as off-farm wage times off-farm labor supply, $E_{o}=w_{o} M=w_{o}(T-F-L)$. Total income of the household is then given as

$$
I=\left[p G(F, H ; A)-w_{h} H\right]+w_{o}(T-F-L)+Z,
$$

where $Z$ is non-labor income (e.g., a direct income payment from government) which is exogenously given.

Substituting equation (1) into the utility function yields

$$
U=U\left(p G(F, H ; A)-w_{h} H+w_{o}(T-F-L)+Z, L\right) .
$$

The objective of the household is to maximize utility by choosing $F, H$, and $L$. The first-order conditions (FOCs) are given, respectively, as

$$
\begin{aligned}
& p G_{F}(F, H ; A)-w_{o}=0, \\
& p G_{H}(F, H ; A)-w_{h}=0, \\
& U_{I}(I, L)\left(-w_{o}\right)+U_{L}(I, L)=0,
\end{aligned}
$$


where $U_{I}=\frac{\partial U(.)}{\partial I}>0$ and $U_{L}=\frac{\partial U(.)}{\partial L}>0 .^{7}$ Equation (3) indicates that the household supplies labor to the farm up to the level where the value of marginal product of on-farm family labor $\left(V M P_{F}\right), p G_{F}$, equals the competitive off-farm wage, $w_{o}$. That is, marginal returns from the onfarm work and off-farm employment are equalized. The shadow wage of on-farm family labor is thus measured by the off-farm wage. Equation (4) indicates that the household hires in labor up to the level where its value of marginal product, $p G_{H}$, equals the hiring-in wage, $w_{h}{ }^{8}$

Given the production technology and the competitive wages, the FOCs in (3) and (4) determine the household's on-farm employment of family labor, $F^{*}$, and hired-in labor, $H^{*}$. This production decision of the farm household is thus independent of its preferences. The separation hypothesis remains valid despite the imperfect substitutability of family and hired labor. These findings contrast with Benjamin (1992), that separation "places no restriction on the mix of family and hired labor” (p. 290) and that there is a non-separation when family and hired labor are imperfect substitutes.

As for utility maximization, the FOC in (5) indicates that the household obtains the most preferred choice at the point where the marginal rate of substitution of leisure for income, $M R S_{L I}\left(=-\frac{d I}{d L}\right)=\frac{U_{L}}{U_{I}}$, equals the “competitive price” of leisure as measured by the off-farm wage, $w_{o}$. The household's optimal decision can be considered as being made in two steps: once $F^{*}$ and $H^{*}$ are determined by equations (3) and (4), the optimal leisure time (denoted as $L^{*}$ ) is determined by equation (5). In other words, family labor is employed on the farm until its marginal product equals $w_{o}$. The family then directs the rest of its labor off-farm, while hired labor is hired in until its marginal product equals $w_{h}$.

Next, we show that the interior equilibrium is unique by examining the second-order

\footnotetext{
${ }^{7}$ An alternative approach is to assume that the household has the following utility function: $U=U(X, L)$, where $X$ is a Hicksian composite good whose price $\left(p_{X}\right)$ is normalized to one. The budget constraint facing the household is $X+w_{o} L=p G(F, H ; A)-w_{h} H-w_{o} F+w_{o} T+Z$, where the left-hand side of the equation is household expenditures on the two consumption goods, $X$ and $L$, and the right-hand side of the equation is the household full income constraint. Solving for $X$, we have $X=p G(F, H ; A)-w_{h} H+w_{o}(T-F-L)+Z$ which is analogous to equation (1). It follows that $U(X, L)=U\left(p G(F, H ; A)-w_{h} H+w_{o}(T-F-L)+Z, L\right)$. The objective of the household is to choose $F, H$, and $L$ that maximize $U(X, L)$. The FOCs are exactly the same as those in (3)-(5). Thus, income in our model can also be expressed in terms of the Hicksian composite good (i.e., a numerarie good) whose price is one. ${ }^{8}$ It follows from the FOCs in (3) and (4) that if $w_{o}>w_{h}$ then $G_{F}>G_{h}$.
} 
conditions. It follows from the FOCs in equations (3) - (5) that we have the Hessian determinant:

$$
\left|D_{3}\right|=\left|\begin{array}{ccc}
p G_{F F} & p G_{F H} & 0 \\
p G_{H F} & p G_{H H} & 0 \\
0 & 0 & J
\end{array}\right|,
$$

where

$$
J=U_{I I}\left(w_{o}\right)^{2}-2 w_{o} U_{I L}+U_{L L}, U_{I I}=\frac{\partial^{2} U}{\partial I^{2}}, U_{I L}=\frac{\partial^{2} U}{\partial I \partial L}, \text { and } U_{L L}=\frac{\partial^{2} U}{\partial L^{2}} .
$$

Given that $w_{o}=\frac{U_{L}}{U_{I}}$ (see the FOC in (5)), we rewrite the term $J$ as follows:

$$
J=U_{I I}\left(\frac{U_{L}}{U_{I}}\right)^{2}-2\left(\frac{U_{L}}{U_{I}}\right) U_{I L}+U_{L L}=\frac{1}{U_{1}^{2}}\left(U_{I I} U_{L}^{2}-2 U_{I} U_{L} U_{I L}+U_{L L} U_{I}^{2}\right)<0 .
$$

The sign of $J$ is unambiguously negative due to the strict convexity of indifference curves. The Hessian matrix is negative definite because

$$
\left|D_{1}\right|=p G_{F F}<0,\left|D_{2}\right|=p^{2}\left(G_{F F} G_{H H}-G_{F H}^{2}\right)>0 \text {, and }\left|D_{3}\right|=\left|D_{2}\right| J<0 \text {. }
$$

Thus the interior solution is indeed unique. The model is complete in that it endogenously determines on-farm employment of family and hired labor $\left(F^{*}\right.$ and $\left.H^{*}\right)$, as well as leisure and off-farm labor supply ( $L^{*}$ and $M^{*}=T-F^{*}-L^{*}$ ). The optimal levels of output, on-farm income, and off-farm wage earnings are given, respectively, as

$$
Q^{*}=G\left(F^{*}, H^{*} ; A\right), y_{f}^{*}=p G\left(F^{*}, H^{*} ; A\right)-w_{h} H^{*} \text {, and } E_{o}^{*}=w_{o}\left(T-F^{*}-L^{*}\right) .
$$

Figure 1 presents a graphical illustration of the unique equilibrium for a farm household. In the upper panel, we have the value-of-total-product (VTP) curve which is determined by $p G($.$) .$ The vertical intercept of the VTP curve is $Z-w_{h} H^{*}$, which reflects non-labor income minus the total wage payment to hired-in labor. The household's optimal choice of production occurs at a point like $E_{F}^{*}$ where the slope of the VTP curve, $p G_{F}$, equals the off-farm competitive wage, $w_{o}$. The household's optimal decisions on off-farm labor supply and leisure occur at a point like $E_{C}^{*}$ where $M R S_{L I}=w_{o}$. In equilibrium, the amounts of time allocated to on-farm work and off-farm employment are given respectively by $F^{*}$ and $M^{*}$, and the amount of leisure that the household consumes is $L^{*}$. Total family income $\left(I^{*}\right)$ is the sum of on-farm income, off-farm labor earnings, and non-labor income, net of the total wage payment to hired labor. The lower panel illustrates 
the marginal condition for on-farm family labor. ${ }^{9}$

\section{Figure 1 about here}

The imperfect substitutability of family and hired labor allows us to determine the equilibrium amounts of the two inputs uniquely. The model indicates that household production and consumption are separable. Despite such a separation, the household's on-farm family labor will be affected by changes in off-farm wage, so will its off-farm labor supply be affected by changes in hiring-in wage and the competitive price of the agricultural product. Furthermore, interactions between on-farm work and off-farm employment directly affect the composition of on-farm income and off-farm labor earnings. In what follows, we examine these questions.

\subsection{Comparative Statics and Its Economic Implications}

To present a comparative static analysis, we take the total differential of the FOCs in equations (3)-(5) and obtain the following:

$$
\left[\begin{array}{ccc}
p G_{F F} & p G_{F H} & 0 \\
p G_{H F} & p G_{H H} & 0 \\
0 & 0 & J
\end{array}\right] \cdot\left[\begin{array}{c}
d F^{*} \\
d H^{*} \\
d L^{*}
\end{array}\right]=\left[\begin{array}{c}
-G_{F} d p+d w_{o} \\
-G_{H} d p+d w_{h} \\
K
\end{array}\right],
$$

where $K$ is given as

$$
\begin{aligned}
K= & {\left[G\left(w_{o} U_{I I}-U_{L I}\right)\right] d p+\left[U_{I}+\left(w_{o} U_{I I}-U_{L I}\right)\left(T-F^{*}-L^{*}\right)\right] d w_{o}-\left(w_{o} U_{I I}-U_{L I}\right) H^{*} d w_{h} } \\
& +\left(w_{o} U_{I I}-U_{L I}\right) d Z .
\end{aligned}
$$

We first examine how changes in external economic conditions and government policies affect the household's decisions on on-farm work, off-farm employment, and leisure. We then examine the resulting impacts on household income and welfare.

\section{(i) Effects on Labor and Production Decisions}

\section{Changes in Non-Labor Income $(Z)$}

It is necessary to analyze the effect of changes in non-labor income in order to identify the

\footnotetext{
${ }^{9}$ The optimal level of hired labor is determined by the equilibrium condition $p G_{H}=w_{h}$, which is not shown in Figure 1.
} 
condition under which leisure is a normal good. Holding constant all the exogenous variables except $Z$, we have from the system in equation (9) that

$$
\begin{aligned}
& \frac{\partial F^{*}}{\partial Z}=\frac{\partial H^{*}}{\partial Z}=0 \\
& \frac{\partial L^{*}}{\partial Z}=\frac{w_{o} U_{I I}-U_{L I}}{J} .
\end{aligned}
$$

Equation (10a) indicates that non-labor income does not affect on-farm family and hired labor. As a result, farm production will not be affected either. ${ }^{10}$ Equation (10b) indicates that the necessary and sufficient condition for leisure to be a normal good is

$$
w_{o} U_{I I}-U_{L I}<0 \text {. }
$$

Unless otherwise specified, we adopt this normality condition. Given that the equilibrium offfarm labor supply is $M^{*}=T-F^{*}-L^{*}$, it is straightforward to show that

$$
\frac{\partial M^{*}}{\partial Z}=-\frac{\partial L^{*}}{\partial Z}<0
$$

These results allow us to establish

PROPOSITION 1. In a competitive economy with no constraints on off-farm employment opportunities, a farm household that receives direct income payment from a governmentally funded program reduces its off-farm labor supply. However, the program does not generate any effect on farm production.

Thus a policy change that reduces direct income payments in an era of tight government budgets affects leisure and off-farm labor supply of a farm household, but not its labor inputs and production. Although production and on-farm income are unaffected, farm households respond to lower income payments by increasing their off-farm labor supplies.

Proposition 1 may explain why after the Uruguay Round of GATT negotiations the emphasis of reforming agricultural production and trade shifted from price subsides to direct income payments. The shift in emphasis is consistent with the results that a direct income payment policy does not affect agricultural supply and hence does not generate any market price distortion like its counterpart of price support. This argument leads one to examine how the removal of a price support program (say, due to agricultural trade liberalization) affects the time

\footnotetext{
${ }^{10}$ We show in Section 3 that these results will not hold up when there are off-farm employment constraints.
} 
allocation and production decisions of a farm household.

\section{Changes in Agricultural Price ( $p$ )}

To analyze output price effects, we use equation (9) and drive the following:

$$
\begin{aligned}
& \frac{\partial F^{*}}{\partial p}=\frac{p\left(-G_{F} G_{H H}+G_{H} G_{F H}\right)}{\left|D_{2}\right|}>(=)(<) 0 ; \frac{\partial F^{*}}{\partial p}>0 \text { if } G_{F H}>0 ; \\
& \frac{\partial H^{*}}{\partial p}=\frac{p\left(-G_{H} G_{F F}+G_{F} G_{H F}\right)}{\left|D_{2}\right|}>(=)(<) 0 ; \frac{\partial H^{*}}{\partial p}>0 \text { if } G_{F H}>0 ; \\
& \frac{\partial L^{*}}{\partial p}=\frac{Q^{*}\left(W_{o} U_{I I}-U_{L I}\right)}{J}>0, \text { if leisure is a normal good. }
\end{aligned}
$$

Given that $M^{*}=T-F^{*}-L^{*}$, we have

$$
\frac{\partial M^{*}}{\partial p}=-\frac{d F^{*}}{d p}-\frac{d L^{*}}{d p}<(=)(>) 0 ; \frac{\partial M^{*}}{\partial p}<0 \text { if } G_{F H}>0 .
$$

The effects of changes in output price on family and hired labor are, in general, indeterminate. If family and hired labor are complements, an increase in output price unambiguously causes both labor inputs to increase. The increase in output price leads the household to consume more leisure, with the result that off-farm labor supply decreases. If family and hired labor are substitutes, we cannot predict unambiguously the output price effects on the two inputs.

It comes as no surprise that farm production increases with output price, regardless of whether family and hired labor are complements or substitutes. Taking the derivative of output with respect to its price, using (11a) and (11b), yields

$$
\frac{\partial Q^{*}}{\partial p}=G_{F} \frac{\partial F^{*}}{\partial p}+G_{H} \frac{\partial H^{*}}{\partial p}=\frac{p\left[-G_{F F}\left(G_{H}\right)^{2}+2 G_{F} G_{H} G_{F H}-G_{H H}\left(G_{F}\right)^{2}\right]}{\left|D_{2}\right|}>0,
$$

where the positive sign follows directly from the strict convexity of isoquants.

We summarize the results of the above analysis in the following proposition:

PROPOSITION 2. For the case in which flexible off-farm employment opportunities are available to a farm household, we have the following results: (i) If family and hired labor are complements, both labor inputs increase with output price; (ii) Output supply curve is upwardsloping; (iii) An increase in output price increases leisure, but the output price effect on the household's off-farm labor supply is generally indeterminate, depending on the technological 
relationship between family and hired labor.

Proposition 2 implies that an agricultural price subsidy program has an ambiguous effect on the labor decisions of a farm household, but the program's effect on farm production is unambiguously positive. This may explain why government intervention in agriculture in the form of price support and/or export subsidies in Western developed countries during the 1980s and early 1990s had resulted in substantial increase in the outputs of agricultural products. The resulting market price distortions had triggered GATT/WTO to reform agricultural production and trade after the Uruguay Round of Multilateral Trade Negotiations. Direct income payments were therefore considered as an alternative policy for price support.

\section{Changes in Off-Farm Wage $\left(w_{o}\right)$}

As mentioned in Section 1, several empirical studies have documented the increasing interactions of farm households with non-farm labor markets. Using the system in (9), we determine the effects of changes in off-farm wage on labor decisions as follows:

$$
\begin{aligned}
& \frac{\partial F^{*}}{\partial w_{o}}=\frac{p G_{H H}}{\left|D_{2}\right|}<0 ; \\
& \frac{\partial H^{*}}{\partial w_{o}}=\frac{-p G_{H F}}{\left|D_{2}\right|}<(>) 0 ; \frac{\partial H^{*}}{\partial w_{o}}<0 \text { if } G_{H F}>0 ; \\
& \frac{\partial L^{*}}{\partial w_{o}}=\frac{U_{I}+\left(w_{o} U_{I I}-U_{L I}\right)\left(T-F^{*}-L^{*}\right)}{J}<(=)(>) 0 ; \\
& \frac{\partial M^{*}}{\partial w_{o}}=-\frac{\partial F^{*}}{\partial w_{o}}-\frac{\partial L^{*}}{\partial w_{o}}<(=)(>) 0 .
\end{aligned}
$$

In view of the results in (12a) - (12d), we have

PROPOSITION 3. An increase in off-farm wage encourages a farm household to reduce onfarm family labor. Household demand for hired labor may not fall, unless family and hired labor are complements. The effects on leisure and off-farm labor supply depend on whether leisure is a normal or an inferior good to the household.

Because an increase in off-farm wage has a negative effect on on-farm family labor, one interesting issue is how the wage increase affects the off-farm labor supply of farm household members - especially spouses. Becker (1981) indicated the trend in the past several decades that 
increasing job opportunities and rising wages for women have significantly increased women's participation in the paid labor markets. In an interesting empirical study, Findeis (2002) found that the majority of farm women in the U.S. are now employed off-farm. Although a bargaining setup with an interaction of labor supplies between spouses would be more appropriate to address the issue, ${ }^{11}$ our simple household model may provide a heuristic explanation. In view of the result in (12d), we find that $\partial M^{*} / \partial w_{o}$ is positive if, and only if, $-\partial F^{*} / \partial w_{o}$ is greater than $\partial L^{*} / \partial w_{o}$. That is, with an increase in off-farm wage, if the reallocation of family labor from onfarm work to off-farm employment exceeds demand for leisure, off-farm labor supply will increase. $^{12}$

Matshe and Young (2004) analyzed the on-farm and off-farm labor decisions of small-scale agricultural household members in Zimbabwe. They found that variables such as gender and education of members in a farm household have different effects on labor market participation and the number of hours supplied to work. Serra, Goodwin, and Featherstone (2005) examined various effects that 1996 U.S. farm policy reforms had on a sample of Kansas farmers. The authors found that the implementation of fixed, decoupled payments tended to reduce the likelihood of off-farm labor market participation. The reduction in agricultural price supports tended to increase the motivation of farmers to work off the farm. The overall effect on off-farm employment participation appeared not to have been large. Applying surveyed data of 276 Iowa farmers to a two-household model, Kwon, Orazem, and Otto (2006) found that for an unforeseen adverse shock to the farm operations, farmers' wives are more likely to join off-farm labor market. Farm husbands were less sensitive to transitory farm income changes, thus less likely to switch to off-farm labor market. But for the case when the permanent farm income was expected to rise, both husbands and wives were less likely to work off-farm. The authors further concluded that farm households adjusted their consumption of leisure to replace transitory lost in their farm income.

\footnotetext{
${ }^{11}$ This point suggests the need for future research to develop agricultural household bargaining models that allow for (i) an interaction of the labor supply decisions of husband and wife with distinct preferences and (ii) the wife's decision to participate in off-farm labor markets. For farm household models that take into account labor supplies of husbands and wives or women's participation in the labor force see, e.g., Huffman (1976), Huffman and Lange (1989), Schultz (1990a, 1990b), Tokle and Huffman (1991), and Udry (1996).

${ }^{12}$ The sign of $\partial L^{*} / \partial w_{o}$ in equation (12c) is, in general, indeterminate, depending on the Hicksian substitution effect and the associated income effect. Here we pay attention to off-farm labor supply in interaction with leisure demand when off-farm wage increases.
} 


\section{Changes in Hiring-in Wage $\left(w_{h}\right)$}

Hired labor is frequently assumed to be a perfect substitute for family labor in the literature (Benjamin, 1992). This assumption makes it difficult to determine a unique solution for hired labor and on-farm family labor. In the model of labor input heterogeneity we consider, we have from equation (9) that the effects of changes in hiring-in wage are:

$$
\begin{aligned}
& \frac{\partial F^{*}}{\partial w_{h}}=\frac{-p G_{F H}}{\left|D_{2}\right|}<(=)(>) 0 \text { if } G_{F H}>(=)(<) 0 \\
& \frac{\partial H^{*}}{\partial w_{h}}=\frac{p G_{F F}}{\left|D_{2}\right|}<0 \\
& \frac{\partial L^{*}}{\partial w_{h}}=\frac{-H^{*}\left(w_{o} U_{I I}-U_{L I}\right)}{J}<0 \\
& \frac{\partial M^{*}}{\partial w_{h}}=-\frac{\partial F^{*}}{\partial w_{h}}-\frac{\partial L^{*}}{\partial w_{h}}>(=)(<) 0
\end{aligned}
$$

First, the effect of an increase in hiring-in wage on on-farm family labor is negative or positive, depending on whether family and hired labor are complements or substitutes. Second, demand for hired labor decreases its wage. Third, an increase in hiring-in wage lowers leisure demand, but the effect on off-farm labor supply is indeterminate. Only when family and hired labor are complements will off-farm labor supply increase with hiring-in wage. But in this case farm production decreases because both on-farm family and hired labor decrease.

\section{(ii) Effects on Total Household Income and Welfare}

To analyze how changes in output price affect household income, we take the derivative of income in equation (1) with respect to $p$, and evaluate the resulting expression at the equilibrium, $\left(F^{*}, H^{*}, L^{*}\right)$, to get

$$
\frac{\partial I^{*}}{\partial p}=\left(p G_{F}-w_{o}\right) \frac{\partial F^{*}}{\partial p}+\left(p G_{H}-w_{h}\right) \frac{\partial H^{*}}{\partial p}+Q^{*}-w_{o} \frac{\partial L^{*}}{\partial p}=Q^{*}-w_{o} \frac{\partial L^{*}}{\partial p} .
$$

If leisure is an inferior good such that $\partial L^{*} / \partial p$ is negative (see (11c)), the sign of $\partial I^{*} / \partial p$ is unambiguously positive. But if leisure is a normal good such that $\partial L^{*} / \partial p$ is positive, there are three possibilities: 


$$
\frac{\partial I^{*}}{\partial p}>(=)(<) 0, \text { if } Q^{*}>(=)(<) w_{o} \frac{\partial L^{*}}{\partial p} .
$$

A change in output price generates two conflicting effects on total household income. A onedollar increase in output price, for example, raises on-farm income by an amount equal to $Q^{*}$. This price increase encourages a household to consume more leisure and hence lower its offfarm income by an amount equal to $w_{o}\left(\partial L^{*} / \partial p\right)$. If $Q^{*}$ is greater than (equal to) (less than) $w_{o}\left(\partial L^{*} / \partial p\right)$, total household income increases (remains the same) (decreases). This explains why the output price effect on total household income $\partial I^{*} / \partial p$ is, in general, indeterminate.

Despite the ambiguous relationship between total income and output price, a decrease (an increase) in output price lowers (raises) household utility. To see this, we take the derivative of utility with respect to $p$ and use the FOC in (5) and the result in (14a) to obtain the following:

$$
\frac{\partial U^{*}}{\partial p}=U_{I} \frac{\partial I^{*}}{\partial p}+U_{L} \frac{\partial L^{*}}{\partial p}=U_{I}\left(Q^{*}-w_{o} \frac{\partial L^{*}}{\partial p}\right)+U_{L} \frac{\partial L^{*}}{\partial p}=U_{I} Q^{*}>0 .
$$

We thus have

PROPOSITION 4. A decrease in output price unambiguously lowers the utility of a farm household. The household's total income may increase if the family significantly increases offfarm labor supply by lowering its leisure.

Proposition 4 indicates the role of off-farm employment in increasing total household income. Another implication concerns the relationship between changes in money income and changes in utility (i.e., welfare). In the farm household model in which income is endogenous and leisure is a normal good, changes in money income and changes in utility may not be "synchronized." This suggests that, under certain circumstances, money income may be inadequate in serving as a measure to reflect the actual change in utility or welfare.

Next, we discuss the effect of changes in off-farm wage on total household income. Taking the derivative of income in equation (1) with respect to $w_{o}$, evaluating the resulting expression at $\left(F^{*}, H^{*}, L^{*}\right)$, yields

$$
\frac{\partial I^{*}}{\partial w_{o}}=\left(p G_{F}-w_{o}\right) \frac{\partial F^{*}}{\partial w_{o}}+\left(p G_{H}-w_{h}\right) \frac{\partial H^{*}}{\partial w_{o}}-w_{o} \frac{\partial L^{*}}{\partial w_{o}}+\left(T-F^{*}-L^{*}\right)=-w_{o} \frac{\partial L^{*}}{\partial w_{o}}+M^{*} .
$$


This sign is indeterminate. The sufficient condition for $\partial I^{*} / \partial w_{o}$ to be positive is

$$
M^{*}>w_{o} \frac{\partial L^{*}}{\partial w_{o}} \text { or } \frac{M^{*}}{L^{*}}>\varepsilon_{L^{*}, w_{o}}\left(\equiv \frac{\partial L^{*}}{\partial w_{o}} \frac{w_{o}}{L^{*}}\right) .
$$

For a one-dollar increase in $w_{o}$, ceteris paribus, total household income increases by an amount equal to the amount of time supplied to off-farm work, $M^{*}$. But the increased wage also leads the household to consume more leisure, with the result that the amount of income forgone is equal to $w_{o}\left(\partial L^{*} / \partial w_{o}\right)$. If $M^{*}$ is greater than $w_{o}\left(\partial L^{*} / \partial w_{o}\right)$, total income increases. ${ }^{13}$ An alternative interpretation is that total income increases if the ratio of $M^{*}$ over $L^{*}$ exceeds the elasticity of demand for leisure with respect to off-farm wage.

With flexible off-farm employment, one question of interest concerns whether a household's utility will increase with the off-farm wage. To see this, we take the derivative of utility with respect to $w_{o}$, using the FOC in (5) that $U_{I} w_{o}=U_{L}$ and (15a), to get

$$
\frac{\partial U^{*}}{\partial w_{o}}=U_{I} \frac{\partial I^{*}}{\partial w_{o}}+U_{L} \frac{\partial L^{*}}{\partial w_{o}}=U_{I}\left(-w_{o} \frac{\partial L^{*}}{\partial w_{o}}+M^{*}\right)+U_{L} \frac{\partial L^{*}}{\partial w_{o}}=U_{I} M^{*}>0 .
$$

It follows from equations (15a) and (15c) that total household income may be decreasing when household utility is increasing. This possibility arises when the household significantly reduces on-farm labor supply by consuming more leisure (see Figure 2). We therefore have

PROPOSITION 5. An increase in off-farm wage is welfare-improving if members of a farm household are employed off the farm, ceteris paribus. Total household income may increase or decrease, depending on the family's decisions on off-farm labor supply and leisure demand.

\section{Figure 2 about here}

As for the impact on household income resulting from changes in hiring-in wage, we have

$$
\frac{\partial I^{*}}{\partial w_{h}}=\left(p G_{F}-w_{o}\right) \frac{\partial F^{*}}{\partial w_{h}}+\left(p G_{H}-w_{h}\right) \frac{\partial H^{*}}{\partial w_{h}}-H^{*}-w_{o} \frac{\partial L^{*}}{\partial w_{h}}=-H^{*}-w_{o} \frac{\partial L^{*}}{\partial w_{h}} .
$$

If leisure is a normal good such that $\partial L^{*} / \partial w_{h}$ is negative, the sign of $\partial I^{*} / \partial w_{h}$ is indeterminate.

\footnotetext{
${ }^{13}$ Chinn (1979) found that off-farm income in Taiwan was the major source of rising agricultural household incomes in the 1970s, even though during the same period real agricultural income also increased because of significant increases in agricultural productivity.
} 
Nevertheless, total household income may increase when the following sufficient condition is satisfied:

$$
\frac{\partial I^{*}}{\partial w_{h}}>0 \text { if } w_{o}\left(-\frac{\partial L^{*}}{\partial w_{h}}\right)>H^{*} .
$$

For a one-dollar increase in $w_{h}$, total income decreases by an amount equal to the amount of hired labor, $H^{*}$. But the increase in hiring-in wage causes leisure to decrease and off-farm labor supply to increase. If the resulting increase in off-farm labor earnings $w_{o}\left(-\partial L^{*} / \partial w_{h}\right)$ is greater than $\mathrm{H}^{*}$, total household income increases. The hiring-in wage effect on total income is indeterminate, but its effect on welfare is unambiguously negative. That is, $\partial U^{*} / \partial w_{h}=-H^{*}<0$.

Next, we discuss what effect a change in non-labor income has on total household income. Unlike farm production and on-farm income, total household income is not independent of nonlabor income. This is because leisure is responsive to changes in non-labor income. Taking the derivative of $I^{*}$ with respect to $Z$ yields

$$
\frac{\partial I^{*}}{\partial Z}=\left(p G_{F}-w_{o}\right) \frac{\partial F^{*}}{\partial Z}+\left(p G_{H}-w_{h}\right) \frac{\partial H^{*}}{\partial Z}+1-w_{o} \frac{\partial L^{*}}{\partial Z}=1-w_{o} \frac{\partial L^{*}}{\partial Z} .
$$

If leisure is a normal good ( $\partial L^{*} / \partial Z>0$ ), the sign of $\partial I^{*} / \partial Z$ cannot be determined unambiguously. That is,

$$
\frac{\partial I^{*}}{\partial Z}>(=)(<) 0, \text { if } 1>(=)(<) w_{o} \frac{\partial L^{*}}{\partial Z} .
$$

For a one-dollar increase in non-labor income, if the amount of income forgone, $w_{o}\left(\partial L^{*} / \partial Z\right)$, is less than (equal to) (more than) that one dollar, total household income increases (remains unchanged) (decreases). Interestingly, household utility increases with non-labor income because $\partial U^{*} / \partial Z=U_{I}>0$.

\section{(iii) Effects on On-Farm Income and Off-farm Labor Earnings}

The empirical studies of Rosenzweig (1988) and many others documented the importance of offfarm income to farm households. One issue of interest concerns how the composition of total household income is affected by changes in external economic conditions. Given that on-farm gross income is $y_{f}^{*}=p Q\left(F^{*}, H^{*}\right)-w_{h} H^{*}$, we have 


$$
\begin{aligned}
& \frac{\partial y_{f}^{*}}{\partial p}=p G_{F} \frac{\partial F^{*}}{\partial p}+G^{*}>(=)(<) 0 ; \frac{\partial y_{f}^{*}}{\partial p}>0 \text { if } G_{F H}>0 ; \\
& \frac{\partial y_{f}^{*}}{\partial w_{o}}=p G_{F} \frac{\partial F^{*}}{\partial w_{o}}+\left(p G_{H}-w_{h}\right) \frac{\partial H^{*}}{\partial w_{o}}=p G_{F} \frac{\partial F^{*}}{\partial w_{o}}<0 ; \\
& \frac{\partial y_{f}^{*}}{\partial w_{h}}=p G_{F} \frac{\partial F^{*}}{\partial w_{h}}-H^{*}>(=)<0 ; \frac{\partial y_{f}^{*}}{\partial w_{h}}<0 \text { if } G_{F H}>0 ; \\
& \frac{\partial y_{f}^{*}}{\partial Z}=p G_{F} \frac{\partial F^{*}}{\partial Z}+\left(p G_{H}-w_{h}\right) \frac{\partial H^{*}}{\partial Z}=0 .
\end{aligned}
$$

We thus have

PROPOSITION 6. On-farm income increases with output price if family and hired labor are complements. An increase in off-farm wage causes the on-farm income to fall. Also, the on-farm income is a decreasing function of hiring-in wage if family and hired labor are complements. Changes in non-labor income, however, do not generate any effect on on-farm income.

With respect to the effects on off-farm labor earnings, $E_{o}^{*}=w_{o} M^{*}$, we have

$$
\begin{aligned}
& \frac{\partial E_{o}^{*}}{\partial p}=w_{o} \frac{d M^{*}}{d p}<(=)(>) 0 ; \frac{\partial E_{o}^{*}}{\partial p}<0 \text { if } G_{F H}>0 \\
& \frac{\partial E_{o}^{*}}{\partial w_{o}}=M^{*}+w_{o} \frac{\partial M^{*}}{\partial w_{o}}>(=)(<) 0 ; \frac{\partial E_{o}^{*}}{\partial w_{o}}>0 \text { if } \eta \equiv \frac{\partial M^{*}}{\partial w_{o}} \frac{w_{0}}{M^{*}}>-1 ; \\
& \frac{\partial E_{o}^{*}}{\partial w_{h}}=w_{o} \frac{\partial M^{*}}{\partial w_{h}}>(=)(<) 0 ; \\
& \frac{\partial E_{o}^{*}}{\partial Z}=w_{o} \frac{\partial M^{*}}{\partial Z}<0 .
\end{aligned}
$$

The implications of the derivatives are summarized in the following proposition:

\section{PROPOSITION 7.}

(i) In the face of a decrease in agricultural price, a farm household can increase its off-farm labor earnings through a reallocation of labor from on-farm work to off-farm employment. The sufficient condition under which off-farm labor earnings increases as product price decreases is when family and hired labor are complements.

(ii) When the off-farm labor supply curve is upward-sloping, an increase in off-farm wage raises off-farm labor earnings. 
(iii) The effect of an increase in hiring-in wage on off-farm labor earnings is indeterminate.

(iv) An increase in non-labor income lowers off-farm labor supply, with the consequence that offfarm labor earnings decrease.

Having discussed the economic implications for the case where off-farm employment opportunities are flexible, we proceed to examine the case where the availability of off-farm employment to a farm household is limited.

\section{Considering Off-Farm Employment Constraints}

\subsection{A Constrained-Optimization Framework}

Our aim in this section is to analyze how the inflexibility of an off-farm work schedule affects a household's time allocation decisions, income, and utility. Let the constrained off-farm work time be exogenously fixed as $M=\bar{M}$. As such, leisure time and total household income become

$$
\begin{aligned}
& L=T-F-\bar{M}, \\
& I=p G(F, H ; A)-w_{h} H+w_{o} \bar{M}+Z .
\end{aligned}
$$

Substituting (20) and (21) into the household's utility function yields

$$
U=U\left(p G(F, H ; A)-w_{h} H+w_{o} \bar{M}+Z, T-F-\bar{M}\right) .
$$

The FOCs for utility maximization with respect to $F$ and $H$ are given, respectively, as

$$
\begin{aligned}
& p G_{F}(F, H ; A)=\frac{U_{L}(I, L)}{U_{I}(I, L)}, \\
& p G_{H}(F, H ; A)-w_{h}=0 .
\end{aligned}
$$

Equation (23a) indicates that on-farm family labor is optimally chosen when its value of marginal product, $p G_{F}$, equals the marginal rate of substitution of leisure for income, $M R S_{L I}\left(=U_{L} / U_{I}\right)$. This optimal decision rule is different from the flexible off-farm employment case discussed in Section 2. Equation (23b) is the usual marginal condition for hired labor. These two FOCs determine the equilibrium on-farm family and hired labor, denoted respectively by $\tilde{F}$ and $\tilde{H}$. Having determined $\tilde{F}$, the optimal consumption of leisure (denoted as $\tilde{L}$ ) is $\tilde{L}=T-\tilde{F}-\bar{M}$. Inspection of the FOCs reveals that decisions on labor inputs and production are not independent of household preferences. This implies that off-farm employment constraints 
are critical to the validity of the separation proposition.

With a binding constraint on off-farm work time, farm shadow wage may no longer be identical to off-farm wage. If a household has a strong (weak) preference over on-farm work, farm shadow wage is likely to be greater (less) than the off-farm wage. Figure 3 presents a graphical interpretation of such a constrained equilibrium. In the upper panel, the exogenous offfarm work time $\bar{M}$ is first deducted from the total time endowment $T$. The off-farm wage $w_{o}$ is given by the slope of the straight line connecting the origin 0 with point 0 '. Point 0 ' serves as a new origin to measure on-farm family labor $\widetilde{F}$ on the horizontal axis. ${ }^{14}$ Originating from point 0 ', we draw a vale-of-total product (VTP) curve, i.e., $p G($.$) . The vertical intercept of the curve$ is $Z-w_{h} \tilde{H}$, which measures non-labor income net of wage payments to hired labor. The household's optimal choice of income and leisure occurs at a point like $E_{3}$, where the VTP curve is tangent to the highest indifference curve possible. At point $E_{3}$, the farm shadow price, measured by the value of marginal product of family labor $V M P_{F}$, is less than the off-farm wage $w_{o}$. For alternative household preferences, equilibrium may occur at a point like $E_{1}$ where the farm shadow wage is greater than the off-farm wage. ${ }^{15}$

\section{Figure 3 about here}

It is necessary to check the second-order sufficient conditions for the constrained equilibrium. The Hessian determinant (denoted as $|S|$ ) is:

$$
|S|=\left|\begin{array}{cc}
R & U_{I} p G_{F H} \\
p G_{H F} & p G_{H H}
\end{array}\right| \text {, where } R=U_{I} p G_{F F}+\frac{1}{U_{I}^{2}}\left(U_{L}^{2} U_{I I}-2 U_{I} U_{L} U_{I L}+U_{I}^{2} U_{L L}\right) \text {. }
$$

Diminishing marginal returns to on-farm family labor $\left(G_{F F}<0\right)$ and the strict quasi-concavity of

\footnotetext{
${ }^{14}$ Figure 3 contrasts with Figure 2 in Benjamin (1992, p. 293) where the optimal mix of family and hired labor is indeterminate. In analyzing the case of a binding constraint on off-farm employment, Benjamin (1992) showed that there is non-separation when family and hired labor are characterized by different efficiencies. But a farm household cannot determine unambiguously its family labor to be employed on the farm, however. Treating family and hired labor as separate inputs, we show that these labor inputs are uniquely determined. We further determine how on-farm family and hired labor change in response to changes in external economic conditions.

${ }^{15}$ Only when household preferences are such that the equilibrium occurs at point like $E_{2}$ will the farm shadow wage coincide with the off-farm wage. Even for this special case, the exogenous $\bar{M}$ is not necessarily identical to the optimal off-farm work time $\left(M^{*}\right)$ discussed in Section 2.
} 
utility imply that the value of $R$ is strictly negative. Strict concavity of the production function further implies that the Hessian is negative definite because

$$
R<0 \text { and }|S|=U_{I} p^{2}\left(G_{F F} G_{H H}-G_{F H}^{2}\right)+\frac{p G_{H H}}{U_{I}^{2}}\left(U_{L}^{2} U_{I I}-2 U_{I} U_{L} U_{I L}+U_{I}^{2} U_{L L}\right)>0 .
$$

Thus the interior solution is unique.

\subsection{Comparative Statics and Its Economic Implications}

Next, we examine how the farm household adjusts its optimal decision to changes external conditions. Taking the total differential of the FOCs in (23a) and (23b) yields

$$
\left[\begin{array}{cc}
R & p U_{I} G_{F H} \\
p G_{H F} & p G_{H H}
\end{array}\right]\left[\begin{array}{l}
d F \\
d H
\end{array}\right]=\left[\begin{array}{c}
N \\
-G_{H} d p+d w_{h}
\end{array}\right],
$$

where the term $R$ is given by (24) and the term $N$ is defined as follows:

$$
\begin{aligned}
N= & {\left[-U_{I} G_{F}+Q\left(U_{L I}-p G_{F} U_{I I}\right) d p+\bar{M}\left(U_{L I}-p G_{F} U_{I I}\right) d w_{o}+w_{o}\left(U_{L I}-p G_{F} U_{I I}\right) d \bar{M}\right.} \\
& -H\left(U_{L I}-p G_{F} U_{I I}\right) d w_{h}+\left(U_{L I}-p G_{F} U_{I I}\right) d Z .
\end{aligned}
$$

In the subsequent analysis, we investigate equilibrium adjustments in the labor and production decisions of the household in response to external economic conditions. We then discuss the resulting impacts on household income and utility.

\section{(i) Effects on Labor and Production Decisions}

\section{Changes in Non-Labor Income $(Z)$}

As in Section 2, we first identify the necessary and sufficient condition for leisure to be a normal good. Given that $\tilde{L}=T-\bar{M}-\tilde{F}$, we have

$$
\frac{\partial \tilde{F}}{\partial Z}=-\frac{\partial \tilde{L}}{\partial Z}
$$

If leisure is a normal good ( $\partial \tilde{L} / \partial Z>0$ ), we have from (26a) that

$$
\frac{\partial \tilde{F}}{\partial Z}<0
$$

which implies that an increase in non-labor income negatively affects on-farm labor supply. Next, we have from equation (25) that 


$$
\frac{\partial \tilde{F}}{\partial Z}=\frac{p G_{H H}\left(U_{L I}-p G_{F} U_{I I}\right)}{|S|}
$$

Using equations (26a)-(26c) and noting that $|S|>0$ and $G_{H H}<0$, we have the necessary and sufficient condition for leisure to be a normal good as follows:

$$
\left(U_{L I}-p G_{F} U_{I I}\right)>0 .
$$

Unless otherwise specified, we assume that this normality condition holds.

It follows from equation (25) that

$$
\frac{\partial \tilde{H}}{\partial Z}=\frac{-p G_{H F}\left(U_{L I}-p G_{F} U_{I I}\right)}{|S|}>(<) 0 \text { if } G_{H F}<(>) 0 .
$$

Given that on-farm family labor decreases with non-labor income (see equation 26(b)), if farm technology is such that family and hired labor are substitutes $\left(G_{H F}<0\right)$, the sign of $d \tilde{H} / d Z$ is positive. In this case, demand for hired labor increases with non-labor income, but farm production cannot be determined unambiguously. If farm technology is such that family and hired labor are complements $\left(G_{H F}>0\right)$, the sign of $d \tilde{H} / d Z$ is negative. In this case, hired labor and farm production unambiguously decrease with non-labor income. These findings contrasts with the case of flexible off-farm employment discussed in Section 2 where changes in non-labor income do not affect (i) on-farm employment of family and hired labor and (ii) farm production. In the presence of off-farm job constraints, a policy prescription that reductions in direct income payments do not affect farm production and on-farm income will no longer be valid.

Woldehanna, Lansink, and Peerlings (2000) examined off-farm work decision, using an unbalanced panel of 4110 observations during 1971 to 1993. Their results indicated that nonlabor income, on-farm labor supplied by other household members, and agricultural education do not have significant influence on off-farm work decision. Also, they discovered that rationing and unexpected transaction costs inhibited farm household to participate off-farm work. Furthermore, the positive impacts on off-farm working decision could be found in family size and general education, but these two factors did not response to the level of off-farm labor income. In a recent contribution, Hennessy and Rehman (2008) investigated the interaction between government subsidies and farmers' time allocation decisions in Irish. Based on the Irish National Farm Survey dataset for 2002, the authors discovered that direct payment made it more likely for farmers to participate in the off-farm job market which could lead to an increase in 
household wealth. But for the case in which farm income decreased, the likelihood of looking for off-farm employment could increase.

\section{Changes in Agricultural Price ( $p$ )}

With respect to output price effects, we use equation (25) to drive the following:

$$
\begin{aligned}
& \frac{\partial \tilde{F}}{\partial p}=\frac{p G_{H H}\left[-U_{I} G_{F}+\tilde{Q}\left(U_{L I}-p G_{F} U_{I I}\right)\right]+p U_{I} G_{H} G_{F H}}{|S|}>(=)(<) 0 \\
& \frac{\partial \tilde{H}}{\partial p}=\frac{-G_{H} R-p G_{H F}\left[-U_{I} G_{F}+\tilde{Q}\left(U_{L I}-p G_{F} U_{I I}\right)\right]}{|S|}>(=)<0 \\
& \frac{d \tilde{L}}{d p}=-\frac{\partial \tilde{F}}{\partial p}>(=)(<) 0
\end{aligned}
$$

Unless leisure is an inferior good and $G_{H F}>0$ such that $d \tilde{F} / d p>0$ and $d \tilde{H} / d p>0$, the output price effects on $\tilde{F}, \tilde{H}$, and $\tilde{L}$ are indeterminate. It is then interesting to see whether or not the output supply curve remains to be upward-sloping. The effect of changes in price on output is:

$$
\begin{aligned}
\frac{\partial \tilde{Q}}{\partial p} & =G_{F} \frac{\partial \tilde{F}}{\partial p}+G_{H} \frac{\partial \tilde{H}}{\partial p} \\
= & \frac{p U_{I}\left(-G_{H H} G_{F}^{2}+2 G_{F} G_{H} G_{F H}-G_{F F} G_{H}^{2}\right)}{|S|}-\frac{G_{H}^{2}}{U_{I}^{2}|S|}\left(U_{I I} U_{L}^{2}-2 U_{I} U_{L} U_{I L}+U_{L L} U_{I}^{2}\right) \\
& +\frac{p \tilde{Q}\left(G_{F} G_{H H}-G_{H} G_{H F}\right)\left(U_{L I}-p G_{F} U_{I I}\right)}{|S|}
\end{aligned}
$$

Unlike the unconstrained case, the sign of $\partial \tilde{Q} / \partial p$ can no longer be determined unambiguously. The sufficient conditions for the output supply curve to slopes upward are: (i) family and hired labor are complements $\left(G_{H F}>0\right)$ and (ii) leisure demand is inferior $\left(U_{L I}-p G_{F} U_{I I}<0\right)$. Given that $\bar{M}$ is fixed, the farm household may respond to an output price increase by increasing its on-farm family labor. This can be achieved by reducing demand fro leisure. If both family and hired labor are complements (condition (i)), farm production, on-farm income, and total household income will increase. In this case, there is a negative relationship between household income and leisure (condition (ii)) so that the output supply curve is upward-sloping.

In analyzing the on-farm and off-farm labor decisions of small-scale agricultural household members in Zimbabwe, Matshe and Young (2004) indicated the importance of farm 
household characteristics such as land area accessible to the family, assets, and the agricultural product prices in affecting the labor market participation decisions of rural household members.

\section{Changes in Off-farm Wage $\left(w_{o}\right)$}

Next, we have from equation (25) that

$$
\begin{aligned}
& \frac{\partial \tilde{F}}{\partial w_{o}}=\frac{p G_{H H} \bar{M}\left(U_{L I}-p G_{F} U_{I I}\right)}{|S|}=\bar{M} \frac{\partial \tilde{F}}{\partial Z}<0 ; \\
& \frac{\partial \tilde{H}}{\partial w_{o}}=\frac{-p G_{H F} \bar{M}\left(U_{L I}-p G_{F} U_{I I}\right)}{|S|}=\bar{M} \frac{\partial \tilde{H}}{\partial Z}>(<) 0 \text { if } G_{H F}<(>) 0 ; \\
& \frac{\partial \tilde{L}}{\partial w_{o}}=-\frac{\partial \tilde{F}}{\partial w_{o}}>0 .
\end{aligned}
$$

With $\bar{M}$ being exogenously fixed, an increase in off-farm wage causes on-farm family labor to fall. This is because of an increase in leisure. Consequently, if family and hired labor are substitutes (complements), demand for hired labor increases (decreases).

\section{Changes in Hiring-in Wage $\left(w_{h}\right)$}

With respect to the effects of changes in hiring-in wage, we have from equation (25) that

$$
\begin{aligned}
& \frac{\partial \tilde{F}}{\partial w_{h}}=\frac{-\tilde{H} p G_{H H}\left(U_{L I}-p G_{F} U_{I I}\right)-p U_{I} G_{F H}}{|S|}>(=)(<) 0 ; \frac{\partial \tilde{F}}{\partial w_{h}}>0 \text { if } G_{H F}<0 ; \\
& \frac{\partial \tilde{H}}{\partial w_{h}}=\frac{R+\tilde{H} p G_{H F}\left(U_{L I}-p G_{F} U_{I I}\right)}{|S|}<(=)(>) 0 ; \frac{\partial \tilde{H}}{\partial w_{h}}<0 \text { if } G_{H F}<0 ; \\
& \frac{\partial \tilde{L}}{\partial w_{h}}=-\frac{\partial \tilde{F}}{\partial w_{h}}<(=)(>) 0 ; \frac{\partial \tilde{L}}{\partial w_{h}}<0 \text { if } G_{H F}<0 .
\end{aligned}
$$

For the case where family and hired labor are substitutes $\left(G_{H F}<0\right)$, an increase in hiring-in wage causes on-farm family labor to increase. Both hired labor and leisure will decrease.

\section{Changes in Off-farm Work Time ( $\bar{M})$}

As for the effects of a change in off-farm work time, we have from equation (25) that

$$
\frac{\partial \tilde{F}}{\partial \bar{M}}=\frac{p G_{H H} w_{o}\left(U_{L I}-p G_{F} U_{I I}\right)}{|S|}=w_{o} \frac{\partial \tilde{F}}{\partial \bar{M}}<0 ;
$$




$$
\begin{aligned}
& \frac{\partial \tilde{H}}{\partial \bar{M}}=\frac{-p G_{H F} w_{o}\left(U_{L I}-p G_{F} U_{I I}\right)}{|S|}=w_{o} \frac{\partial \tilde{H}}{\partial Z}>(<) 0 \text { if } G_{H F}<(>) 0 \\
& \frac{\partial \tilde{L}}{\partial \bar{M}}=-1-\frac{\partial \tilde{F}}{\partial \bar{M}}>(<) 0 .
\end{aligned}
$$

Interestingly, an increase in $\bar{M}$ has a negative effect on on-farm family labor and a positive effect on consuming leisure. If family and hired labor are substitutes (complements), demand for hired labor increases (decreases). The effect on leisure is ambiguous, however.

We summarize these findings in the following proposition:

PROPOSITION 8. In the presence of a binding constraint on off-farm employment, household production and consumption are no longer separable. Consequently, we have the following results (i) The effects of a change in agricultural price on labor input decisions, leisure demand, and farm production can no longer be determined unambiguously; (ii) On-farm family labor, hired labor, and farm production are no longer independent of non-labor income; (iii) Demand for hired labor may not be a decreasing function of the hiring-in wage unless family and hired labor are substitutes; and (iv) An exogenous increase in off-farm work time has a negative effect on on-farm family labor.

\section{(ii) Effects on Total Household Income and Welfare}

Next, we examine various effects on income and utility. Given that total household income is $\tilde{I}=\tilde{y}_{f}+w_{o} \bar{M}+Z$, where $\tilde{y}_{f}\left(=p G(\tilde{F}, \tilde{H} ; A)-w_{h} \tilde{H}\right)$ is on-farm gross income, we have

$$
\frac{\partial \tilde{I}}{\partial p}=\frac{\partial \tilde{y}_{f}}{\partial p}=\tilde{Q}+p G_{F} \frac{\partial \tilde{F}}{\partial p}+\left(p G_{H}-w_{h}\right) \frac{\partial \tilde{H}}{\partial p}=\tilde{Q}+p G_{F} \frac{\partial \tilde{F}}{\partial p}>(=)(<) 0 .
$$

The output price effect on total income (or on-farm gross income) is indeterminate because the derivative $\partial \tilde{F} / \partial p$ is ambiguous in sign (see equation (27a)). This finding suggests that the efficacy of government price subsidies in raising total household income is indeterminate unless the following sufficient condition is satisfied:

$$
\tilde{Q}>-p G_{F}(\partial \tilde{F} / \partial p) .
$$

But the output price effect on household utility is positive since $\partial \tilde{U} / \partial p=U_{I} \tilde{Q}>0$.

As for the effect of changes in off-farm wage on total household income, we have 


$$
\frac{\partial \tilde{I}}{\partial w_{o}}=\frac{\partial \tilde{y}_{f}}{\partial w_{o}}+\bar{M}=p G_{F} \frac{\partial \tilde{F}}{\partial w_{o}}+\bar{M}
$$

Because $\partial \tilde{F} / \partial w_{o}$ is negative (see equation (28a)), the sign of $\partial \tilde{I} / \partial w_{o}$ is indeterminate. The sufficient condition under which $\partial \tilde{I} / \partial w_{o}$ is positive is: $\tilde{M}>-p G_{F}\left(\partial \tilde{F} / \partial w_{o}\right)$. But an increase in $w_{o}$ unambiguously increases household welfare since $\partial \tilde{U} / \partial w_{o}=U_{I} \tilde{M}>0$.

With respect to the effects of a change in hiring-in wage on income and utility, we have

$$
\frac{\partial \tilde{I}}{\partial w_{h}}=\frac{\partial \tilde{y}_{f}}{\partial w_{h}}=p G_{F} \frac{\partial \tilde{F}}{\partial w_{h}}-\tilde{H}
$$

If family and hired labor are complements, it is possible for $\partial \tilde{F} / \partial w_{h}$ to be negative in sign (see equation (29a)) so that total household income decreases with hiring-in wage. But if family and hired labor are substitutes such that $\partial \tilde{F} / \partial w_{h}$ is positive, total household income may not increase with hiring-in wage unless the following sufficient condition holds: $p G_{F}\left(\partial \tilde{F} / \partial w_{h}\right)>\tilde{H}$. But an increase in $w_{h}$ always lowers utility since $\partial \tilde{U} / \partial w_{h}=-U_{I} \tilde{H}<0$.

Given that $\partial \tilde{F} / \partial Z<0$ (see equation (26b)), the effect of a change in non-labor income on total household income is indeterminate as illustrated by the following derivative:

$$
\frac{\partial \tilde{I}}{\partial Z}=\frac{\partial \tilde{y}_{f}}{\partial Z}+1=p G_{F} \frac{\partial \tilde{F}}{\partial Z}+1
$$

The sufficient condition under which total household income increases with non-labor income is: $1>-p G_{F}(\partial \tilde{F} / \partial Z)$. An increase in non-labor income increases welfare since $\partial \tilde{U} / \partial Z=U_{I}>0$.

Finally, we examine how changes in $\bar{M}$ affect household income. We have

$$
\frac{\partial \tilde{I}}{\partial \bar{M}}=\frac{\partial \tilde{y}_{f}}{\partial \bar{M}}+w_{o}=p G_{F} \frac{\partial \tilde{F}}{\partial \bar{M}}+w_{o} .
$$

Other things being equal, an exogenous increase in $\bar{M}$ raises off-farm labor earnings. However, the increase in $\bar{M}$ lowers $\tilde{F}$ (see equation (30a)), which causes farm production and hence onfarm income to fall. ${ }^{16}$ If the increase in off-farm labor earnings more than offsets the decrease in

\footnotetext{
${ }^{16}$ Low (1981) found for the case of southern Africa that increases in rural non-farm employment opportunities in some communities resulted in a decrease in agricultural production and income. Further increases in non-farm employment are likely to increase total household income but may instead lower farm production and on-farm income.
} 
on-farm income, total household income increases. That is, $\partial \tilde{I} / \partial \bar{M}>0$ if $w_{o}>-p G_{F}(\partial \tilde{F} / \partial \bar{M}) .{ }^{17}$ It is straightforward to show that $\partial \tilde{U} / \partial \bar{M}=U_{I} w_{o}>0$. We thus have

PROPOSITION 9. An exogenous increase in off-farm work time, $\bar{M}$, increases total household income when the off-farm wage, $w_{o}$, is higher than the decrease in on-farm income resulting from a reallocation of family labor from on-farm work to off-farm employment, $-p G_{F}(\partial \tilde{F} / \partial \bar{M})$. However, the increase in $\bar{M}$ increases household utility.

Using the 2000 General French Census of Agriculture, Benjamin and Kimhi (2006) examined labor decisions for farm work, off-farm work, and hired farm labor. They found that farm family composition played an important role in affecting farm women's labor supply decisions and that off-farm labor was negatively related to farm size. Moreover, they found that hired labor was positively associated with farm size, specialization, and status as a partnership. This implies that factors outside the farm sector (such as immigration policy) might indirectly affect the structural change in French farms. The authors also found that farm operators and farm spouses were substitutes and that hired labor is substitute to both male and female farm labor. In a recent contribution, Lien, Kumbhakar, and Hardaker (2010) studied the factors that influence the farm households' off-farm working decision, and how off-farm work influences farm production. They collected panel data set from Norwegian grain farms during 1991 to 2005. Their results showed that age, marital status, number of children, farming region, and farm output influenced off-farm work decisions. However, they did not find sufficient evidence to proof that off-farm work had negative impacts on farm production and farm income.

\section{Concluding Remarks}

In this paper, we examine the relationship between farm production, income, and utility of a farm household in an input-heterogeneity model where on-farm family and hired labor, off-farm labor supply, and leisure are jointly and uniquely determined. Paying attention to interactions between on-farm work and off-farm employment, we analyze how the household adjusts its decisions on

\footnotetext{
${ }^{17}$ Schultz (1990) showed that earnings from off-farm employment play a prominent role in reducing income variability of agricultural households. Mishra and Goodwin $(1997,2002)$ further documented a positive relationship between off-farm employment and farm income variability.
} 
labor supply and production in response to changes in external economic conditions. We compare differences in household decisions for the two alternative settings with and without constraints on off-farm labor employment opportunities. Our analysis extends the incomeleisure model of Benjamin (1992), and complements the theoretical models by Strauss (1986), Lopez (1996), Huffman (1980, 1991), and Taylor and Adelman (2003).

In the analysis, we find that the imperfect substitutability of family and hired labor is not critical to a separation between household production and consumption. This finding suggests that empirical studies showing that family and hired labor are imperfect substitutes are insufficient to undermine the separation proposition. We find that the critical factors are constraints on off-farm employment opportunities. We also point out that, regardless of a separation, a farm household's decisions on on-farm family and hired labor are affected by changes in off-farm wages. So will the household's off-farm labor supply be affected by changes in hiring-in wages and the competitive prices of agricultural products. We show how interactions between on-farm work and off-farm employment affect on-farm income and off-farm labor earnings.

The simple models of a farm household have policy implications. First, a policy change that results in a decrease in agricultural price (e.g., due to the removal of a price support program or an agricultural trade liberalization policy) unambiguously lowers household utility. A farm household may respond to the policy change by increasing its participation in local off-farm labor markets in order to increase off-farm labor earnings. A better understanding of how farm households allocate their time between farming and off-farm jobs in reaction to changes in economic conditions may be crucial for designing successful farm policies that improve farm income or reduce income variability of farm families. Second, for the case in which off-farm employment is flexible, increasing direct income payments unambiguously lowers off-farm labor supply and hence reduces off-farm labor earnings. Third, the argument that reducing direct income payments will not affect farm production is valid when off-farm employment opportunities are available to farm households without constraints. However, this argument does not hold when off-farm job opportunities are limited. The reason is that farm production and direct income payments will no longer be independent. In this case, production and on-farm income may be affected negatively when direct income payments are reduced or eliminated.

The limitations of this paper and hence possible extensions should also be mentioned. First, 
the paper does not take into account elements of imperfect information and the farm household's attitudes toward risk under uncertainty. It is likely that the production and consumption decisions become non-separable (Mishra and Goodwin, 1997; Benjamin and Kimhi, 2006). Second, the analysis focuses on time allocation from a household's perspective without addressing issues on gender division of farm labor. ${ }^{18}$ Third, we anticipate that imperfect labor markets would alter the separability nature of the household decisions, similar to the case with off-farm employment constraints. It might also be worthwhile to take into account minimum wage regulations in the off-farm labor markets when investigating how the public policies would affect the time allocation decision of a farm household. ${ }^{19}$

\footnotetext{
${ }^{18}$ See the interesting analysis contribution Udry (1996).

${ }^{19}$ Compliance and noncompliance behavior of non-farm producers subject to the minimum wage laws can also be considered when analyzing the labor supply decisions of farm households to non-farm work. For studies on the behavior of complying and noncomplying minimum-wage firms, see, e.g., Chang and Ehrlich (1985) and Chang (1992), Yaniv (2001, 2004), and Chang and Walia (2007). See also Basu, Genicot, and Stiglitz (1999) for an interesting analysis of household labor supply and minimum wage legislation.
} 


\section{References}

Ahearn, M. and John E. Lee, Jr. (1991). "Multiple Job-Holding Among Farm Operator Households in the United States.” In: Multiple Job-Holding Among Farm Families, M. Hallberg, J. Findeis, and D. Lass (Eds.). Ames: Iowa State University Press.

Anderson, D. and M. W. Leiserson. (1984). "Rural Nonfarm Employment in Developing Countries.” Economic Development and Cultural Change, 28, 227-248.

Barkley, A. (1990). "The Determinants of the Migration of Labor Out of Agriculture in the United States, 1940-85.” American Journal of Agricultural Economics, 72, 568-573.

Barnham, H. and L. Squire. (1979). "An Econometric Application of the Theory of the Farm Household.” Journal of Development Economics, 6, 79-102.

Basu, K., G. Genicot, and J. E. Stiglitz. (1999). "Household Labor Supply, Unemployment and Minimum Wage Legislation.” Policy Research Working Paper Series (Number 2049), The World Bank.

Benjamin, C. and A. Kimhi. (2006). "Farm work, off-farm work, and hired farm labour: Estimating a discrete-choice model.” European Review of Agricultural Economics, 33, 149-171.

Benjamin, D. (1992). "Household Composition, Labor Markets, and Labor Demand: Testing for Separation in Agricultural Household Models.” Econometrica, 60, 287-322.

Becker, G. S. (1981). A Treatise on the Family. Cambridge, MA: Harvard University Press.

Bowles, S. (1970). "Migration as Investment: Empirical Tests of the Human Investment Approach to Geographical Mobility.” Review of Economics and Statistics, 52, 356-362.

Caillavet, F., H. Guyomard, and R. Lifran. (eds). (1994). Agricultural Household Modeling and Family Economics. Amsterdam: Elsevier.

Chang, Y.-M. (1992). "Noncompliance Behavior of Risk-Averse Firms under the Minimum Wage Law.” Public Finance Review, 20, 390-401.

Chang, Y.-M. and I. Ehrlich. (1985). "On the Economics of Compliance with the Minimum Wage Law.” Journal of Political Economy, 93, 84-91.

Chang, Y.-M. and B. Walia. (2007). "Wage Discrimination and Partial Compliance with the Minimum Wage Law,” Economics Bulletin, 10, 1-7.

Chinn, D. L. (1979). "Rural Poverty and the Structure of Farm Household Income in Developing Countries: Evidence from Taiwan.” Economic Development and Cultural Change, 27, 283-301.

Deolalikar, A. and V. P. M. Vijverberg. (1983). "The Heterogeneity of Family and Hired Labor in 
Agricultural Production: A Test Using District-Level Data from India,” Journal of Economic Development, 8, 45-69.

Deolalikar, A. and V. P. M. Vijverberg. (1987). "A Test of the Heterogeneity of Family and Hired Labor in Asian Agriculture.” Oxford Bulletin of Economics and Statistics, 49, 291-305.

Eswaran, M. and A. Kotwal. (1986). “Access to Capital and Agrarian Production Organization.” Economic Journal, 96, 482-498.

Fafchamps, M. and A. R. Quisumbing. (1999). "Human Capital, Productivity, and Labor Allocation in Rural Pakistan.” Journal of Human Resources, 34, 369-406.

Findeis, J. L. (2002). “Farm Women in the United States.” Paper presented at the 2002 USDA Ag Update Forum, February, Washington, D.C.

Frisvold, G. B. (1994). "Does Supervision Matter? Some Hypothesis tests using Indian FarmLevel Data.” Journal of Development Economics, 43, 217-238.

Gardner, B. (1992). "Changing Economic Perspectives on the Farm Problem.” Journal of Economic Literature, 30, 62-101.

Hallberg, M. C., J. L. Findeis; and D. A. Lass (eds). (1991). Multiple Job-holding Among Farm Families. Ames: Iowa State University Press.

Hennessy, T. C. and T. Rehman. (2008). “Assessing the Impact of the 'Decoupling' Reform of the Common Agricultural Policy on Irish Farmers' Off-farm Labor Market Participation Decisions.” Journal of Agricultural Economics, 59, 41-56.

Huffman, W. E. (1976). “The Value of the Productive Time of Farm Wives.” American Journal of Agricultural Economics, 58, 836-841.

Huffman, W. E. (1980). "Farm and Off-Farm Work Decisions: The Role of Human Capital." Review of Economics and Statistics, 62, 14-23.

Huffman, W. E. (1991). “Agricultural Household Models: Survey and Critique.” In Multiple JobHolding Among Farm Families, edited by M.C. Hallberg, J. L. Findeis, and D. A. Lass, Ames: Iowa State University Press, 1991, 79-111.

Huffman, W. E. and M. D. Lange. (1989). “Off-farm Work Decisions of Husbands and Wives: Joint Decision Making” Review of Economics and Statistics, 71, 471-480.

Jacoby, H. G. (1993). "Shadow Wages and Peasant Family Labor Supply: Application to the Peruvian Sierra.” Review of Economic Studies, 60, 903-921.

Kwon, C-W, P. F. Orazem, and D. M. Otto. (2006). "Off-farm Labor Supply Responses to Permanent and Transitory Farm Income.” Agricultural Economics, 34, 59-67. 
Lien, G., S. C. Kumbhakar, and J. B. Hardaker. (2010). "Determinants of Off-farm Work and its Effects on Farm Performance: The Case of Norwegian Grain Farmers.” Agricultural Economics, 41, 577-586.

Lopez, R. E. (1984). "Estimating Labor Supply and Production Decisions of Self-Employed Farm Producers.” European Economic Review, 24, 61-82.

Lopez, R. E. (1986). "Structural Models of the Farm Household That Allow for Interdependent Utility and Profit-maximization Decisions.” In: Singh, Inderjit; Lyn Squire; and John Strauss (eds.), Agricultural Household Models: Extensions, Applications, and Policy. Baltimore: Johns Hopkins University Press.

Low, A. R. C. (1981). "The Effects of Off-Farm Employment on Farm Incomes and Production: Taiwan Contrasted with Southern Africa.” Economic Development and Cultural Change, 29, 741-47.

Matshe, I. and T. Young (2004), "Off-farm Labor Allocation Decisions in Small-Scale Rural Households in Zimbabwe,” Agricultural Economics, 30,175-186.

Mishra, A. K. and B. K. Goodwin. (1997). "Farm Income Variability and the Supply of Off-Farm labor.” American Journal of Agricultural Economics, 79, 880-887.

Mishra, A. K. and C. L. Sandretto. (2002). "Stability of Farm Income and the Role of Nonfarm Income in U.S. Agriculture.” Review of Agricultural Economics, 24, 208-221.

Nakajima, C. (1969). "Subsistence and Commercial Family Farms: Some Theoretical Models of Subjective Equilibrium.” In: Subsistence Agriculture and Economic Development, ed. by C. F. Wharton. Chicago: Aldine.

Nakajima, C. (1986). Subjective Equilibrium Theory of the Farm Household. Amsterdam: Elsevier.

Newman, J. L. and P. J. Gertler. (1994). "Family Productivity, Labor Supply, and Welfare in a Low Income Country.” Journal of Human Resources, 29, 989-1026.

Rosenzweig, M. R. (1988). "Labor Markets in Low-Income Countries.” In: Hollis Chenery and T.N. Srinivasan (eds.), Handbook of Development Economics Vol. 1, Amsterdam: North-Holland.

Schultz, T. P. (1990a). "Women's Changing Participation in the Labor Force." Economic Development and Cultural Change, 38, 451-488.

Schultz, T. P. (1990b). "Testing the Neoclassical Model of Family Labor Supply and Fertility," Journal of Human Resources, 25, 599-634.

Schultz, T. P. (1999). "Women's Role in the Agricultural Household: Bargaining and Human Capital.” Center Discussion Paper No. 803, Economic Growth Center, Yale University. 
Serra, T., B. Goodwin, and A. Featherstone (2005). “Agricultural Policy Reform and Off-Farm Labor Decisions,” Journal of Agricultural Economics, 56, 271-287.

Singh, I., L. Squire, and J. Strauss (eds.). (1986). Agricultural Household Models: Extensions, Applications, and Policy. Baltimore: Johns Hopkins University Press.

Strauss, J. (1984). "Joint Determination of Food Consumption and Production in Rural Sierra Leone.” Journal of Development Economics, 14, 77-103.

Strauss, J. (1986). “The Theory of Comparative Statics of Agricultural Household Models: A General Approach.” In: I. Singh, L. Squire, and J. Strauss (eds.), Agricultural Household Models: Extensions, Applications and Policy, Baltimore: The Johns Hopkins Press, 71-94.

Sumner, D. A. (1982). "The Off-Farm Labor Supply of Farmers.” American Journal of Agricultural Economics, 64, 499-509.

Taylor, J. E. and I. Adelman. (2003). “Agricultural Household Models: Genesis, Evolution, and Extensions.” Review of Economics of Household, 1, 33-58.

Tokle, J., G. and W. E. Huffman. (1991). "Local Economic Conditions and Wage Labor Decisions of Farm and Rural Nonfarm Couples.” American Journal of Agricultural Economics, 73, 652-670.

Udry, C. (1996). “Gender, Agricultural Production and the Theory of the Household.” Journal of Political Economy, 104 (October), 1010-1046.

Woldehanna, T., A. O. Lansink, and J. Peerlings. (2000). “Off-farm Work Decisions on Dutch Cash Crop Farms and the 1992 and Agenda 2000 CAP reforms.” Agricultural Economics, 22, 163-171.

Yaniv, G. (2001) "Minimum Wage Noncompliance and the Employment Decision” Journal of Labor Economics 19, 596-603.

Yaniv, G. (2004) "Minimum Wage Noncompliance and the Sub-minimum Wage Rate" Economics Bulletin 10(9), 1-7.

Yotopoulos, P. A. and L. J. Lau. (1974). "On Modeling the Agricultural Sector in Developing Economics.” Journal of Development Economics, 1, 105-127. 


\section{Figure 1}

Time allocation decision of the agricultural household

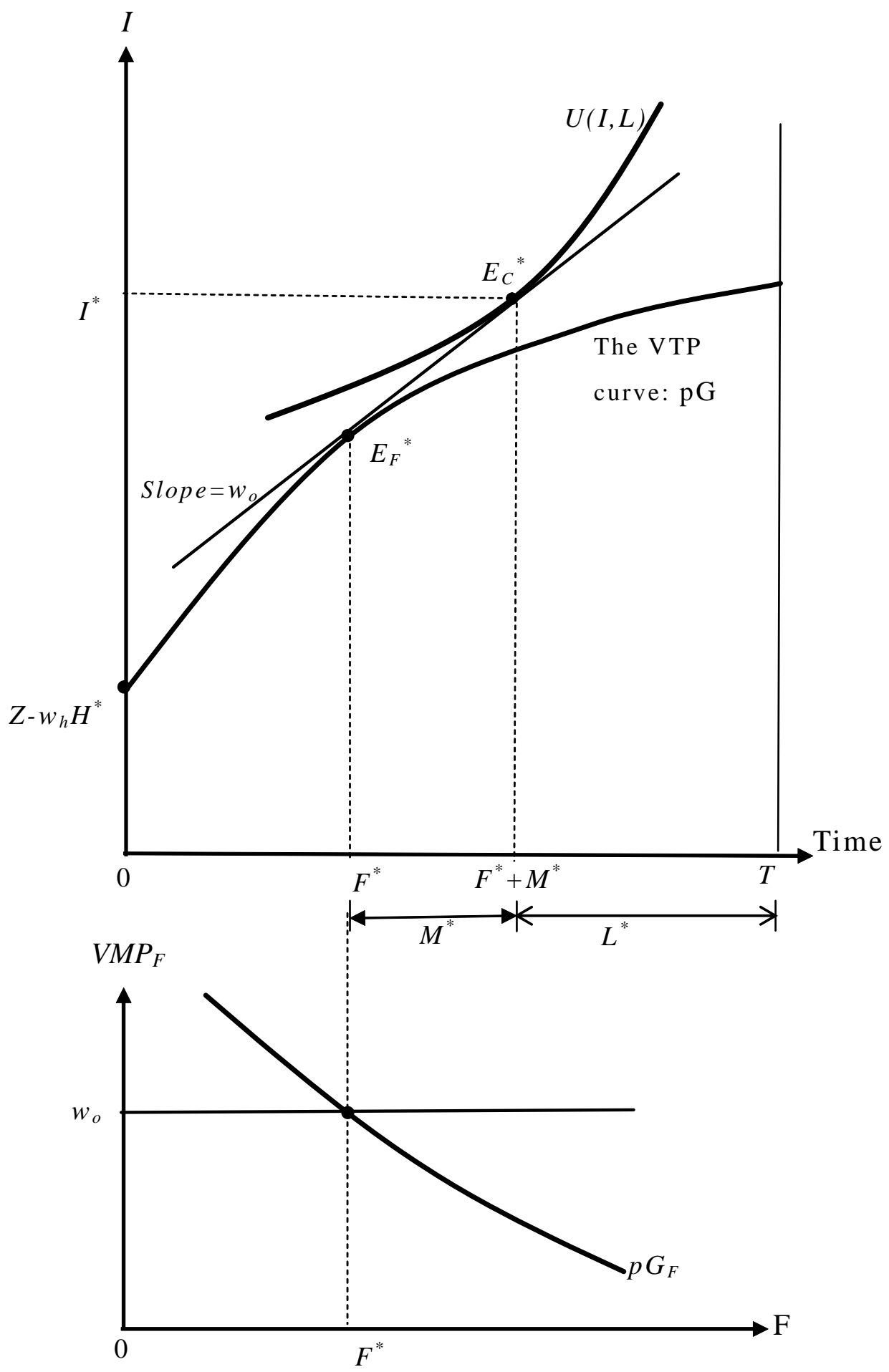


Figure 2

The case of an increase in utility with a decrease in total income (when the off-farm wage increases)

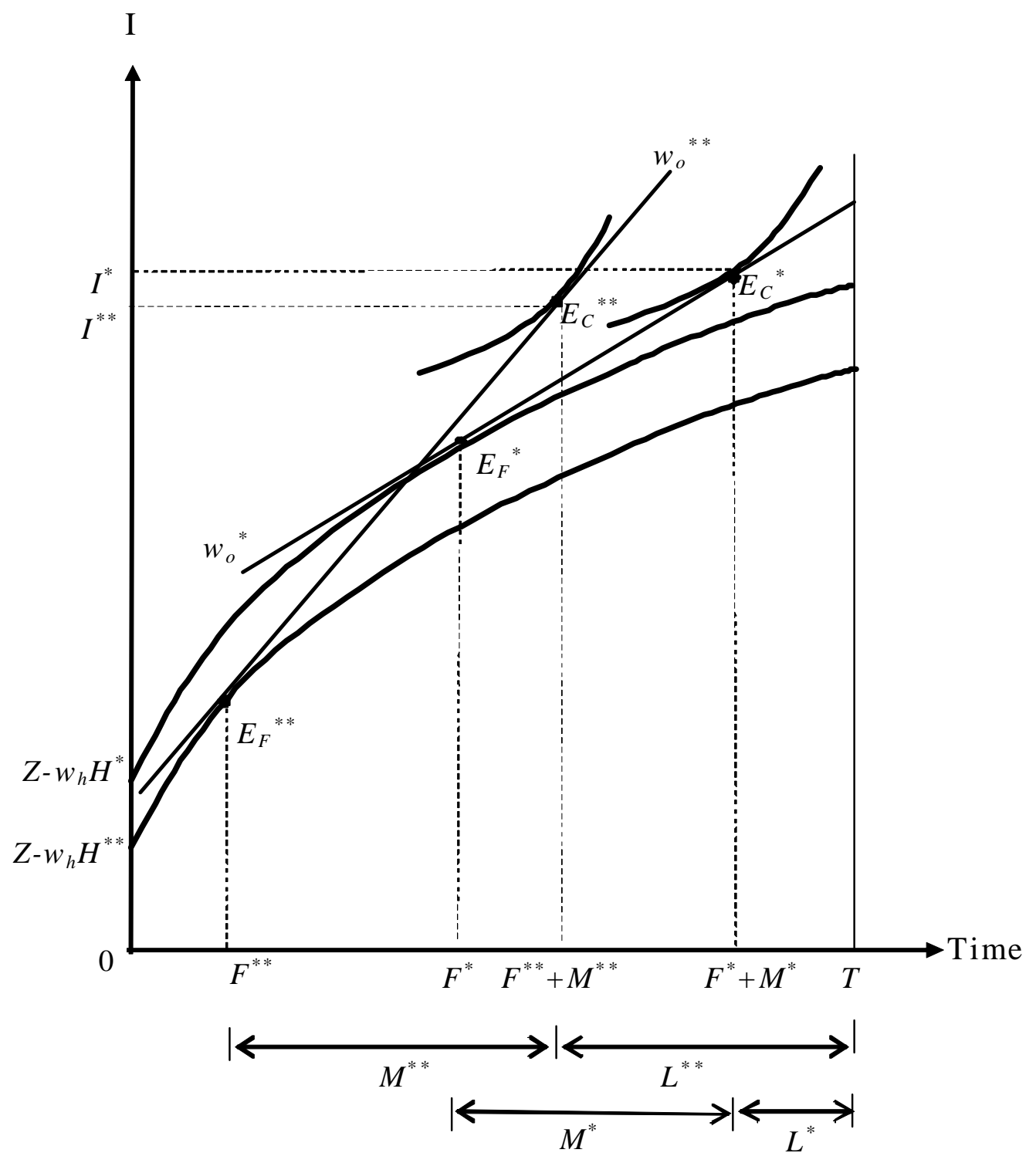




\section{Figure 3}

Labor and production decisions in the presence of off-farm employment constraints

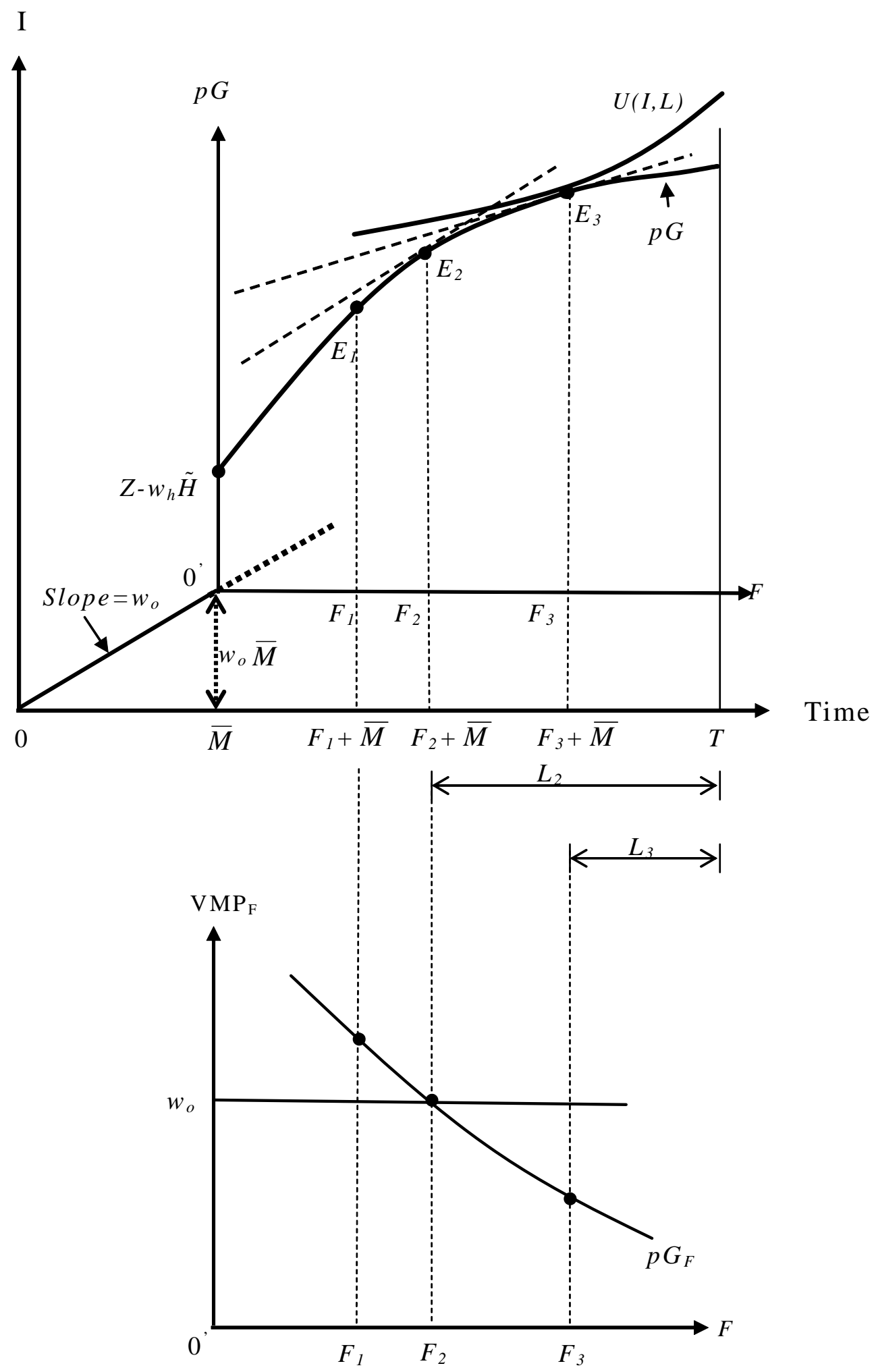

